\title{
Contrast-enhanced Ultrasound in Obstetrics and Gynecology
}

\author{
Jun Murotsuki \\ Department of Obstetrics and Gynecology, Iwate Medical University School of Medicine, Morioka, Japan
}

Correspondence: Jun Murotsuki

Associated Professor, Department of Obstetrics and Gynecology, Iwate Medical University School of Medicine, 19-1 Uchimaru, Morioka, Iwate 020-8505, Japan

Telephone: +81-19-651-5111, Fax: +81-19-622-1900, e-mail: junmuro@iwate-med.ac.jp

\begin{abstract}
Ultrasonography is a well-established imaging modality for evaluation of gynecologic tumors. In recent years, more sophisticated technologies like the use of intravascular contrast agents led to an improvement in the ability of the practitioner to differentiate benign from malignant masses. When we consider the safety of contrastenhanced ultrasonography in obstetrics and gynecology, we must discuss about the effect of ultrasound contrast media on embryo and fetus. The use of ultrasound contrast media in pregnant women always concerns in the obstetricians because of the principle of not exposing a fetus to any drug. Therefore, the literature was reviewed for information about those safety and efficacy because of the uncertainty about the use of contrast media during pregnancy. Based on the limited information available, mutagenic and teratogenic effects have not been described after administration of ultrasound contrast media. No effect on the fetus has been seen after contrast media. The small potential risk associated with the nonthermal bioeffects via acoustic cavitation may be considered to prohibit the use in first trimester pregnant women. In previous studies including human trials, no evidence of adverse effect was reported. Contrast-enhanced ultrasonography could prove a useful adjunct in multiple gestations and in evaluation of uteroplacental circulation. It appears to be very promising potential in obstetrics.
\end{abstract}

Key words: Contrast media, ultrasonography, obstetrics, gynecology, placental blood flow.

\section{INTRODUCTION}

The recent introduction of high-quality ultrasonic diagnostic equipment and ultrasound contrast media is expected to improve the utility of ultrasonography in a variety of clinical area. Ultrasound contrast agents have been used extensively in internal medicine to enhance cardiovascular imaging, such as echocardiography for imaging of cardiac cavities and valves, ${ }^{1}$ visualization of the coronary arteries, ${ }^{2}$ assessment of myocardial perfusion and viability, ${ }^{3}$ and imaging of carotid atherosclerotic plaque formation. ${ }^{4}$ Other areas in which ultrasound contrast agents have been used include the liver and spleen $^{5}$ and the brain. ${ }^{6}$ Because ultrasonography itself has low contrast resolution, it is difficult to directly visualize tumors and to differentiate between the tumor and normal tissue using ultrasound. Contrast-enhanced ultrasonography offers great promise in oncology for many potential clinical applications. Contrast media enhancement affords the direct depiction of tumor neovascularity. Tumor neovascularity demonstrates clustered vessels of irregular caliber. The procedures has been shown to improve imaging of breast cancer ${ }^{7}$ and prostate cancer. $^{8}$

Contrast-enhanced ultrasonography could also offer great advantages in gynecologic cancers. Combined morphologic and vascular imaging improves early detection and preoperative assessment of ovarian cancer. ${ }^{9,10}$ Because contrast agents increase the sensitivity of detection of parametrial invasion and lymph node metastases, vaginal ultrasound probably now could pay an important role in the evaluation of uterine cervical cancer. ${ }^{11}$ Apart from neoplasms, a lot of authors have reported the clinical values of imaging of the uterine cavity and fallopian tubes. ${ }^{12-14}$ Their use in obstetrics is, however, very limited at the moment because of safety. When ultrasound investigations using contrast media are considered during pregnancy, the principal anxiety for the safety of the fetus relates to the harmful effects related to the ultrasound contrast agent, although they have been shown to markedly enhance placental imaging in a laboratory set-up. Anxiety usually relates to the potential mutagenic and teratogenic effects during early pregnancy.

When we consider the safety of contrast-enhanced ultrasonography in obstetrics and gynecology, we must discuss about the effect of ultrasound contrast media on embryo and fetus. The use of ultrasound contrast media in pregnant women always concerns in the obstetricians because of the principle of not exposing a fetus to any drug. Therefore, the literature was reviewed for information about those safety, efficacy and limitations because of the uncertainty about the use of contrast media during pregnancy. 


\section{ULTRASOUND CONTRAST AGENTS}

The subject of a contrast effect of ultrasound contrast agents is micron-ordered gas microbubbles. Microbubbles are very small compared with ultrasound wave length, and their acoustic feature is completely different from that of the living body. Microbubbles are strongly echogenic, have a high degree of echogenicity, which is the ability of an object to reflect the ultrasound waves effectively. The echogenic difference between the gas in the microbubbles and the soft tissue surroundings of the body is immense. Thus, ultrasound imaging using microbubble contrast agents enhances the ultrasound backscatter, or reflection of the ultrasound waves, to produce a unique sonogram with increased contrast.

In the 1980s and the early 1990s, they used isotonic saline and carbon dioxide beaten manually as contrast media. Indeed, all media having a different echogenicity from that of the living body can be used as contrast media. Contrast media are divided into two groups as hypoechoic and hyperechoic. Isotonic saline and dextran solutions belong to the hypoechoic group. Sonohysterography is a technique developed to better image the uterine cavity. It uses an infusion of sterile saline through a soft plastic catheter placed in the cervix in conjunction with transvaginal ultrasound. The saline infusion distends the uterine cavity and provides an excellent contrast to the lining, giving improved visualization of uterine and endometrial pathology. ${ }^{15}$ This technique may also be used to assess the fallopian tubes by demonstrating fluid spill into the pelvis.

Hyperechoic contrast media containing microbubbles enhance echo signals, allowing detection of the flow by both B-mode and Doppler ultrasound. Commercially available echoenhanced microbubble contrast agents include Albunex (Mallinckrodt, St. Louis, MO, USA), an albumin-shelled ultrasound contrast agents composed of air-filled microbubbles with a median diameter of 3 to $4 \mu \mathrm{m}$; Optison (NycomedAmersham, Oslo, Norway), a second-generation perfluorocarbon-filled contrast agents with similar microbubble diameter and concentration; and Levovist (Schering, Berlin, Germany), a galactose-based air-filled microbubble contrast agents, $99 \%$ of which is smaller than $7 \mu \mathrm{m}$. Unfortunately, Levovist is an only contrast media which we can use at this time in Japan.

\section{SAFETY OF CONTRAST MEDIA IN OBSTETRICS}

No mutagenic effects were shown in vitro with albumin contained in Albunex and galactose and palmitic acid contained in Levovist themselves, using both bacterial testing and sister chromatoid exchange methods. ${ }^{16}$ In vivo tests in animals have shown no evidence of either mutagenic or teratogenic effects with the contrast agents. An Australian categorization of risk of drug use in pregnancy ${ }^{17}$ treats galactose and palmitic acid of radiographic agents as category $B_{2}$, suggesting no increase in the frequency of malformation or other direct or indirect harmful effects on the human fetus and no evidence of an increased occurrence of fetal damage in animal studies.

Although ultrasonography is considered safe during pregnancy, as ultrasound energy has been shown not to be harmful for the developing fetus, ultrasound can produce a variety of nonthermal bioeffects via acoustic cavitation. Cavitation bubbles may induce cell death or transient membrane permeabilization (sonoporation) on a single cell level, as well as microvascular hemorrhage and disruption of tissue structure. In theory transient cavitation can, however, occur under diagnostically relevant conditions if appropriate nuclei exist in the exposed medium. The likelihood of producing cavitationtype nonthermal effects is enhanced by the presence in the sound-field of ultrasound contrast agents. Miller et al showed that both Levovist and Albunex could provide nuclei for inertial cavitation and that the sonochemical hydrogen peroxide was detected after exposure to ultrasound in vitro. ${ }^{18}$ Sonochemicals resulting from ultrasound-induced initial cavitation, with Albunex, have mutagenic potential in cultured cell. ${ }^{19}$ Fortunately, there is no evidence of cavitation effects occurring in the soft tissues of the fetus when exposed to conventional diagnostic ultrasound. However, the possibility exists that such effects may be enhanced by the introduction of ultrasound contrast agents. $^{20}$

Levovist has been shown to be safe in adult because its constitute agents are all naturally occurring and nontoxic. ${ }^{21}$ Microbubble contrast media such as Levovist and Albunex are small enough to pass through capillaries but large enough to preclude transmembranous passage. In absence of an active transport mechanism, Levovist cannot cross the placenta and thus will delineate either fetal or maternal side of the circulation. In fetal sheep experimental model, the contrast agent Levovist caused no emboli in any fetal tissues or in the placenta. ${ }^{22}$ The animal model study using reported that intravenous injection of Albunex does not cause any effect on the fetus of cynomolgus monkey in early pregnancy. ${ }^{23}$ Another study using primates reported that administration of Levovist does not affect fetal hemodynamic parameters as measured by Doppler ultrasound and suggested that administration of the microbubble agent does not interfere with placental blood flow. ${ }^{24}$ In human, Orden et $a l^{25}$ reported that contrast agent enhancement in the examination of uteroplacental perfusion does not produce any harmful fetal or placental effects in late pregnancy.

The safe use of ultrasound contrast media during pregnancy has not been established. While imaging the fetus in the first trimester, contrast agents should be avoided due to the possibility of their mutagenicity. During second and last trimesters, they should not be used unless the benefits outweigh the risks. 


\section{ANIMAL AND EX VIVO MODELS}

Although obstetric applications have been excluded from clinical trials, ultrasound contrast agents could be clinically useful for diagnosis of pathologic placental conditions, including placenta abruptio and abnormalities of placental blood flow. Many researchers conducted a preclinical safety and limited efficacy study using ultrasound contrast agents in a variety of animal models.

In cynomolgus monkey, intravenous injection of Albunex enhanced the color Doppler images of intervillous flow in early pregnancy. $^{23}$ In late pregnant macaques, Levovist that stays within the vascular space and does not cross the placenta could permit differentiation between the maternal and fetal portions of the placenta and might be clinically useful for diagnosis of placental abnormalities. ${ }^{24}$ Ragavendra et $a l^{26}$ applied targeted contrast enhanced ultrasound technique to third trimester gravid rhesus monkey and assessing intervillous blood flow. It is important to evaluation of the blood flow to the intravillous space because its decrease could lead to growth restriction and fetal death. Contrasted ultrasound with video densitometry might be able to measure the intervillous blood flow by constructing of time-intensity curves in pregnant baboons. ${ }^{27}$ With Levovist injections, researchers could show changes in flow in small vessels in a fetal sheep model during hypoxic stress. $^{22}$

Placental lobules from term human placentas were maintained ex vivo with fetal and maternal flow. Albunex ${ }^{28}$ or Levovist $^{29}$ into the fetal vasculature enables color or power Doppler imaging echoenhancement both in chorionic vessels and within the villous tree. Both in animal models and in ex vivo placental experiments, they could delineate placental vasculature with the microbubble contrast agents.

\section{CONTRAST-ENHANCED ULTRASOUD APPLIED HUMAN}

Up to the present date, there are two groups which have reported contrast-enhanced ultrasound applied pregnant women. Orden et $a l^{30}$ reported that Levovist could enhance uteroplacental blood flow imaging, but they could not find any association between fetal growth restriction and intensity changes or absolute intensity parameters. On the other hand, Denbow et $a l^{31,32}$ used ultrasound contrast agents to demonstrate fetofetal transfusion in monochorionic twins. With use of Levovist in human fetuses there was evidence of contralateral twin echo enhancement in the cases of twin-to-twin transfusion syndrome. No evidence of adverse reaction was noted. ${ }^{32}$

Another use of ultrasound contrast agents in obstetrics include diagnoses in ectopic pregnancies ${ }^{33}$ and placenta accreta. $^{34}$ Ultrasound demonstration of the fallopian tubes is possible only if they are filled with fluid or blood. The use of
Levovist could facilitate localization of trophoblastic tissue in ectopic pregnancy. ${ }^{33}$ Contrast-enhanced color flow mapping was informative in the diagnosis of placenta accreta. ${ }^{34}$

\section{CONCLUSIONS}

Ultrasound contrast media are widely used in clinical area including the field of gynecology for diagnostic ultrasonography. In obstetrics, indications of contrastenhanced ultrasonography are still limited because of uncertainly about the use of the contrast media during pregnancy. In previous studies including human trials, no evidence of adverse effect was reported. Contrast-enhanced ultrasonography could prove a useful adjunct in multiple gestations and in evaluation of uteroplacental circulation. It appears to be very promising potential in obstetrics.

\section{REFFERENCES}

1. Miller P, Nanda NC. Contrast echocardiography: new agents. Ultrasound Med Biol 2004;30:425-34.

2. Cwajg J, Xie F, O'Leary E, et al. Detection of angiographically significant coronary artery disease with accelerated intermittent imaging after intravenous administration of ultrasound contrast materials. Am Heart J 2000;139:675-83.

3. Mulvagh SL, DeMaria AN, Feinstein SB, et al. Contrast echocardiography: current and future applications. J Am Soc Echocardiogr 2000;13:331-42

4. Feinstein SB. The powerful microbubble: from bench to bedside, from intravascular indicator to therapeutic delivery system, and beyond. Am J Physiol 2004;287:H450-7.

5. Blomley MJ, Albrecht T, Cosgrove D, et al. Stimulated acoustic emission to image a late liver- and spleen-specific phase of Levovist in normal volunteers and patients with and without liver disease. Ultrasound Med Biol 1999;25:1341-52.

6. Eyding J, Wilkening W, Postert T. Brain perfusion and ultrasonic imaging techniques. Eur J Ultrasound 2002;16:91-104.

7. Kedar RP, Cosgrove DO, McCready VR, et al. Microbubble contrast agent for color Doppler US: effect on breast masses. Radiology 1996;198:679-86.

8. Aranink RG, Beelage HP, de la Rosete JJ, et al. Contrast angiosonography: a technology to improve Doppler ultrasound examinations of the prostate. Eur Urol J 1999;35:9-20.

9. Suren A, Osmers R, Kulenkampff D, et al. Visualization of blood flow in small ovarian tumor vessels by transvaginal color Doppler sonography after echo enhancement with injection of Levovist. Gynecol Obstet Invest 1994;38:210-12

10. Kuspesic S, Kurjak A. Contrast-enhanced, three-dimensional power Doppler sonography for differentiation of adnexal masses. Obstet Gynecol 2000;96:452-58.

11. Testa AC, Ferrandina G, Fruscella E, et al. The use of contrasted transvaginal sonography in the diagnosis of gynecologic diseases. J Ultrasound Med 2005;24:1267-78.

12. Ayida G, Harris P, Kennedy PS, et al. Hysterosalpingo-contrast sonography (HyCoSy) using Echovist 200 in the outpatient 
investigation of infertility patients. Ultrasound Obstet Gynecol 1999;14:200-204.

13. Reis MM, Soares SR, Cancado ML, et al. Hysterosalpingocontrast-sonography (HyCoSy) with SHU 454 (Echovist $\left.{ }^{\circledR}\right)$ for the assessment of tubal pregnancy. Hum Reprod 1998;13:304956.

14. Boudghene FP, Bazot M, Robert Y, et al. Assessment of fallopian tube patency by HyCoSy: comparison of a positive contrast agent with saline solution. Ultrasound Obstet Gynecol 2002;20:386-9.

15. Parsons AK, Lense JJ. Sonohysterography for endometrial abnormalities: preliminary results. J Clin Ultrasound. 1993;21:8795.

16. Marberger M, Stackl W, Hruby W, et al. Ultrasonic lithotripsy and soft tissue. World J Urol 1985;3:27-32

17. Prescribing Medicines in Pregnancy, 4th edition. Australian categorisation of drugs. http://www.tga.gov.au/docs/html/mip/ medicine.htm\#misc

18. Miller DL, Thomas RM. Ultrasound contrast agents nucleate inertial cavitation in vitro. Ultrasound Med Biol 1995;21:105965 .

19. Doida Y, Marcello KR, Brayman AA, et al. Sonochemicals increase the mutation frequency of V79 cells in vitro. Ultrasound Med Biol 1998;24:1209-13.

20. Barnett SB, Rott HD, ter Haar GR, et al. The sensitivity of biological tissues to ultrasound. Ultrasound Med Biol 1997;23:805-12.

21. Schlief R. The use of Levovist (SH U 508A) for echoenhancement of vascular Doppler imaging in clinical diagnosis. Angiology 1996;47:S3-8.

22. Grussner S, Klingmuller V, Bohle R. Increased signal intensity of velocity measurements in duplex sonography by using the contrast agent levovist: a prospective, randomized study in a fetal sheep model. Rofo 2004;176:91-7.

23. Simpson NA, Nimrod C, De Vermette R, et al. Sonographic evaluation of intervillous flow in early pregnancy: use of echoenhancement agents. Ultrasound Obstet Gynecol 1998;11:204208.
24. Schmiedl UP, Komarniski K, Winter TC, Luna JA, et al. Assessment of fetal and placental blood flow in primates using contrast enhanced ultrasonography. J Ultrasound Med 1998;17:75-80.

25. Orden MR, Leinonen M, Kirknen P. Contrast-enhanced ultrasonography of uteroplacental circulation does not evoke harmful CTG changes or perinatal events. Fetal Diagn Ther 2000;15:139-45.

26. Ragavendra N, Tarantal AF. Intervillous blood flow in the third trimester gravid rhesus monkey (Macaca mulatta): use of sonographic contrast agent and harmonic imaging. Placenta 2001;22:200-5.

27. Barth WH, McCurnin DC, Dee Carey K, et al. Contrast sonography, video densitometry and intervillous blood flow: a pilot study. Placenta 2006;27:719-26.

28. Abramowicz JS, Phillips DB, Jessee LN, et al. Sonographic investigation of flow patterns in the perfused human placenta and their modulation by vasoactive agents with enhanced visualization by the ultrasound contrast agent Albunex. J Clin Ultrasound 1999;27:513-22.

29. Denbow ML, Eckersley R, Welsh AW, et al. Ex vivo delineation of placental angioarchitecture with the microbubble contrast agent Levovist. Am J Obstet Gynecol 2000;182:966-71.

30. Orden MR, Gudmundsson S, Kirkinen P. Intravascular ultrasound contrast agents: an aid in imaging intervillous blood flow? Placenta 1999;20:235-40.

31. Denbow ML, Blomley MJ, Cosgrove DO, et al. Ultrasound microbubble contrast angiography in monochorionic twin fetuses. Lancet 1997;349:773.

32. Denbow ML, Welsh AW, Taylor MJ, et al. Twin fetuses: intravascular microbubble US contrast agent administrationearly experience. Radiology 2000;214:724-8.

33. Orden MR, Gudmundsson S, Helin HL, et al. Intravascular contrast agent in the ultrasonography of ectopic pregnancy. Ultrasound Obstet Gynecol 1999;14:348-52.

34. Kirknen P, Helin-Martikainen HL, Vanninen R, et al. Placenta accreta: imaging by gray-scale and contrast-enhanced color Doppler sonography and magnetic resonance imaging. J Clin Ultrasound 1998;26:90-4. 